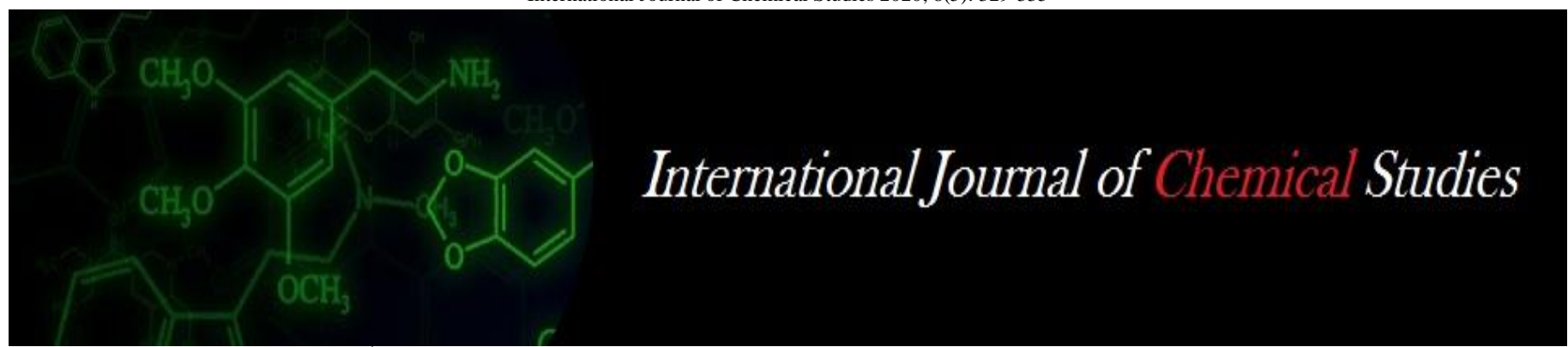

P-ISSN: 2349-8528

E-ISSN: 2321-4902

www.chemijournal.com

IJCS 2020; 8(5): 329-335

(C) 2020 IJCS

Received: 21-06-2020

Accepted: 29-07-2020

\section{S Kumar}

ICAR-Indian Institute of Farming System Research, Modipurm, Meerut, Uttar Pradesh, India

\section{Shamim}

ICAR-Indian Institute of Farming System Research, Modipurm, Meerut, Uttar Pradesh, India

\section{P Kashyap}

ICAR-Indian Institute of Farming System Research, Modipurm, Meerut, Uttar Pradesh, India

\section{P Punia}

ICAR-Indian Institute of Farming System Research, Modipurm, Meerut, Uttar Pradesh, India

\section{AL Meena}

ICAR-Indian Institute of Farming System Research, Modipurm, Meerut, Uttar Pradesh, India

LK Meena

ICAR-Indian Institute of Farming System Research, Modipurm- Meerut, Uttar Pradesh, India

\section{Chethan Kumar}

ICAR-Indian Institute of Farming System Research, Modipurm- Meerut, Uttar Pradesh, India

\section{AS Panwar}

ICAR-Indian Institute of Farming System Research, Modipurm, Meerut, Uttar Pradesh, India

Corresponding Author: S Kumar

ICAR-Indian Institute of Farming System Research, Modipurm, Meerut, Uttar Pradesh, India

\section{Assessment of performance of crop model and meteorological indicators in forecasting potato yield in Western Uttar Pradesh}

\author{
S Kumar, M Shamim, P Kashyap, P Punia, AL Meena, LK Meena, \\ Chethan Kumar and AS Panwar
}

DOI: https://doi.org/10.22271/chemi.2020.v8.i5e.10315

\begin{abstract}
This paper presents a new Integrated Farming System (IFS) ver. 1.1 model and data that could meet the needs of growing community of end-users exemplified by set of potato crop growers. This farm simulation model was used to analyse the effects of nutrient amendment, pond soil on yield of potato and effect of climatic parameters like sunshine and rainfall on crop performance which was then used to calibrate the model for experimental field of institute's experimental site. Using data the model was validated over next year crop cycle at the farm scale. This study also deals with the discussion that how the integrated farming system (IFS) ver. 1.1 model is developed simulating the situations faced by farmers of western Uttar Pradesh with desired technological modifications needed to boost the farmers' productivity and profitability on sustainable basis. By management practices which are in control and practically feasible by farmers for example: like date of sowing and application of non-chemical nutrient amendments, farmers can earn better net profitability with lesser annual cost of cultivation with overall holistic benefit- cost ratio. The results reveal that technological interventions on the basis of land use planning; the system can fetch better gains and livelihood through their farms. This model can act as an innovative tool to transform less remunerative farm production systems into highly remunerative systems using available farm resources to generate better farm gains on sustainable basis. Suggested model can also be useful in teaching processes involved in the system and its behaviour in response input variables.
\end{abstract}

Keywords: Crop models, yield, climate, validation, productivity, profitability

\section{Introduction}

This paper deals with the discussion that how the integrated farming system (IFS) ver. 1.1 model has been developed simulating the entire farm based situations faced by innovative farmers of western Uttar Pradesh with desired technological modifications needed to boost the farmers' productivity and profitability on sustainable basis. Through integration of potato crop and practically feasible farm enterprises, better net profitability with lesser annual cost of cultivation with overall holistic higher B: C ratio under (IFS) ver. 1.1 models can be obtained (Sunil Kumar, et al., 2015) ${ }^{[12]}$. These results revealed that induction of IFS principles and technological interventions on the basis of land use planning, the system can fetch better gains and livelihood through their farms. IFS ver. 1.1 model can act as an innovative tool to transform less remunerative farm production systems into highly remunerative systems using available farm resources to generate better farm gains on sustainable basis towards a new generation of agricultural system data models (J. Miller, 2007) ${ }^{[13]}$.

An important role for crop models is the estimation of yield potential and yield gaps at the site, regional and national levels, identification of reasons for the gaps and evaluation of management options for closing those gaps. Yield potential (Yp), also called potential yield, is the yield of a crop cultivar when grown with water and nutrients non-limiting and biotic stress effectively controlled (Athanasiadis, I.N., 2015) ${ }^{[2]}$.

Crop phenology is the most important means to study the impact of weather on crop plants. It is the study of the timing of recurring natural phenomena such as flowering or senescence of a crop. Information of crop phenology is essential for evaluating crop productivity and crop management (Wheeler T. et. al. 2013) ${ }^{[17]}$. 
Systems science is the study of real world "systems" that consist of components defined by specialists. These components interact with one another and with their environment to determine overall system behavior (Wallach et al. 2014) ${ }^{[16]}$. An agricultural system, or agro-ecosystem, is a collection of components that has as its overall purpose the production of crops and raising livestock to produce food, fiber, and energy from the Earth's natural resources. Such systems may also cause undesired effects on the environment (J.E. Graft 1917) ${ }^{[8]}$.

On farm - farming systems' characterization survey of the country as a whole and western plain zone of Uttar Pradesh revealed that there is either stagnation or reduction in productivity and profitability of the important crops. Because of poverty, the small land holders are reluctant to adopt new technologies. Farming system is a resource management strategy to achieve economic and sustained production to meet diverse requirements of farm households while preserving resource base and maintaining a high level environmental quality (M. Singh 2005) ${ }^{[15]}$. An agricultural system is synthetic (man-made) system, embedded in the natural and social systems. It is defined as "an assemblage of components which are united by some form of interaction and interdependence" (McConnel and Dillon, 1997) ${ }^{[6]}$.

Information and computer technology (ICT) is changing at a rapid pace. Digital technologies allow people to connect across the globe at high speeds at any time (Gartner, 2016) ${ }^{[7]}$. High performance computing can be used to process large amounts of data in a short time frame, to make sense of large quantities of structured and unstructured data (i.e. "big data"; NESSI, 2012) ${ }^{[3]}$ collected using new sensing technologies, and to scale and validate models in ways not previously possible. As a result of these and other developments, society expects more and higher-quality information to be available in support of daily decision-making (M Carley Kathleen 1996) [4]

\section{Materials and methods}

The field experiment was conducted in 2013-2014 and 2012015 at Indian Institute of Farming System Research
Modipuram, Meerut research farm (at $29^{\circ} 08^{\prime}, \mathrm{N}$ latitude and $77^{\circ} 41^{\prime} \mathrm{E}$ longitude at an altitude of $237 \mathrm{~m}$ above mean sea level) U.P., India. The region has a semi-arid sub-tropical climate with an average annual temperature of $16.8^{\circ} \mathrm{C}$. The highest mean monthly temperature $\left(38.9^{\circ} \mathrm{C}\right)$ is recorded in May, and the lowest mean monthly temperature $\left(4.5^{\circ} \mathrm{C}\right)$ is recorded in January. The average annual rainfall is about 665 to $726 \mathrm{~mm}$ (constituting $44 \%$ of pan evaporation) of which about $80 \%$ is received during the monsoon period. The predominant soil at the experimental site is classified as sandy loam in texture. Soil samples for $0-15 \mathrm{~cm}$ depth at the site were collected and tested prior to applying treatments and the basic properties were low available nitrogen, low organic carbon, and medium in available phosphorus, available potassium and alkali in reaction. Fig. 1 a \& b depicted the metrological condition of the season.

The phenological phases (or stages) of plant development and the observations thereof were recorded by visiting the field frequently from sowing to harvesting. Different phenophases like seed germination, emergence of seedlings, emergence and number of leaves, flag leaf emergence, and tuber maturity were recorded. In the seed bed, germination, seedling emergence and emergence of leaf in the main stem were also recorded. In case of record to get the phenological observations a set of plants were tagged with aluminium sheet in each plot to record the dates of appearance of various phenophases.

Statistical analysis: The data generated through the field experiment for two seasons were processed and analyzed individually as well as on pooled basis to ascertain the high yielding cultivar and the optimum date of sowing with respect to tuber yield and above ground biomass yield. Comparisons were made between simulated data of various parameters viz., yield, and periodic dry matter, above ground biomass production, periodical and maximum, leaf area index tuber per pod, and test tuber weight and their corresponding observed data through regression analysis (Sunil Kumar 2015) ${ }^{[12]}$.

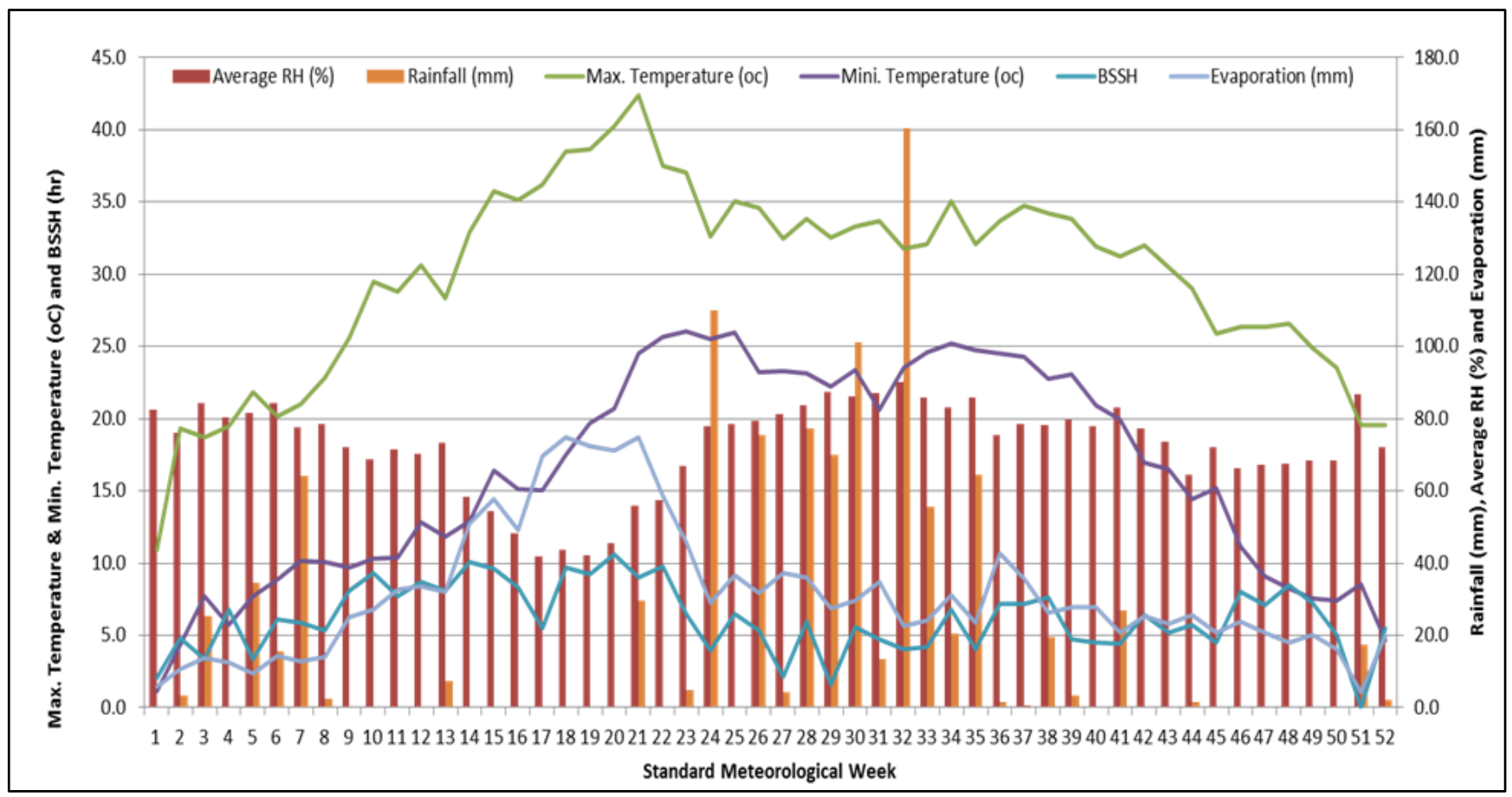

Fig 1a: Metrological condition of the season 2013-14 


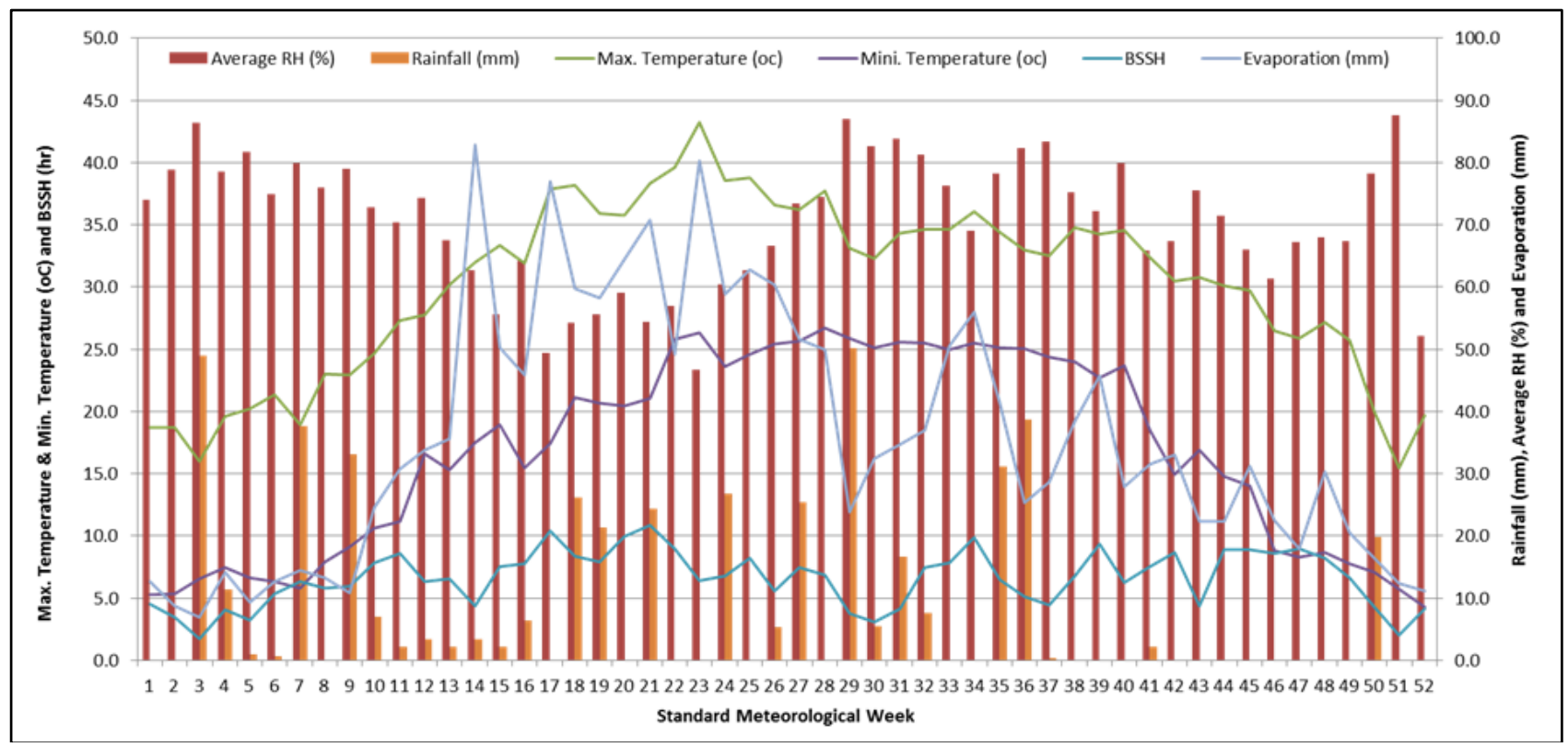

Fig 1b: Metrological condition of the season 2014-15

Validation of the model: Validation is the comparison of the results of model simulations with observations from crop that was not used for the calibration. A model should be rigorously validated under widely differing environmental conditions to evaluate the performance of major processes in addition to its ability to predict yield (Timsima and Humphreys, 2003). Before any model can be used with confidence, adequate validation or assessment of the magnitude of the errors that may result from its use should be performed. Model validation, in its simplest form is a comparison between simulated and observed values.

Beyond comparisons, there are several statistical measures available to evaluate the association between predicted and observed values. Among them correlation coefficient (r) and its square, the coefficient of determination $\left(\mathrm{R}^{2}\right)$ are widely used parameters. (Willmott 1982) has pointed out that the main problem with this analysis is that the magnitudes of $r$ and $\mathrm{r}^{2}$ are not consistently related to the accuracy of prediction where accuracy is defined as the degree to which model predictions approach the magnitudes of their observed counterparts.

IFS Simulator ver.1.1 model: A computer based crop model IFSS (Integrated Farming Systems Simulators) was used to simulate the growth, development and yield of potato under middle Meerut agro-climatic region by taking into account the effects of weather, management and genetics. Since the focus of this research is on performance of selected cultivar and applications of this model under middle Meerut agro-climatic region, therefore Tuber yield, vegetative growth, and physiological maturity was switched off during simulation. Since the initial configuration of the model was suited to simulate the performance of longer duration cultivar of crop, it couldn't be fitted for above selected cultivar under this agro-climatic region as such. Efforts were made to create the required input files and to modify several initial values pertaining to the weather, soil, genotypes and management practices. Minimum crop performance data set are required for determining the values of the phonology coefficients initially and then the values of the coefficients describing growth and reproductive development include dates of emergence, beginning of maximum vegetation, Physiological maturity and tuber yield. The procedure for determining genetic coefficients involved in running the model using a range of values of each coefficient, in the order indicated above, until the desired level of agreement between simulated and observed values was reached. Iterations for the coefficients were stopped when the agreement reached \pm 10 $\%$. For the present study the cultivar genetic coefficients based on field experimental data of first crop season spring, 2013-14 for Chipsona-3 cultivar of potato had been carried out under experimentation.

IFSS Ver.1.1 consists of many different applications, including data programs, crop simulation models and analysis programs for Agro-technology transfer. The following is a very brief description of IFSS models (Fig. 2\&3). The main elements in the design techniques are identification of critical inputs and their interactions, software engineering for developing algorithm, calibration, verification and validation of the developed computational model.

Software engineering for developing algorithm: The general methodology for computational modeling system is the design techniques are identification phase, conceptualization phase, formalization, system design \& development, testing/evaluation and prototype revision phase. Theoretical concepts and computational methods that describe, represent and simulate the functioning of real-world processes; computer simulations in agriculture system are becoming a 'third way' of performing research, expanding thus traditional experimental and theoretical approaches: simulation can be regarded as a numerical experiment, but it often requires advancements in theory simulations can provide information which is impossible or too expensive to measure, as well as insights which are not amenable or too complicated for analytical theory methods models are simplified abstractions of reality representing or describing its most important/driving elements and their interactions simulations can be regarded as model runs for certain initial conditions (real or designed).

Traditional modelling placed emphasis on mathematical modeling with most models based on partial differential equations. As the vast majority of mathematical models are not solvable analytically, approximate methods and numerical methods are the alternative. Unless the solution behaves smoothly, it may be intractable even with approximate 
methods. In this case, the only feasible approach is numerical solution. However, even though we can in principle solve a complex system numerically; this does not mean it is trivial in practice. In fact, most research efforts in the last few decades have dedicated to finding the most efficient methods in solving complex systems.

Calibration, verification and validation: Shaalan Khaled et al. $2004^{[11]}$ studied that these three steps, calibration, verification and validation are the important steps to bring accurate simulation models. A base model should be created and calibrated so that it matches the area being studied. The calibrated model should then be verified to ensure that the model is operating as expected based on the inputs. Verification is a set of techniques for determining the validity of computational models predictions relative to a set of real data. To verify a model the models predictions are compared graphically or statistically with the real data.

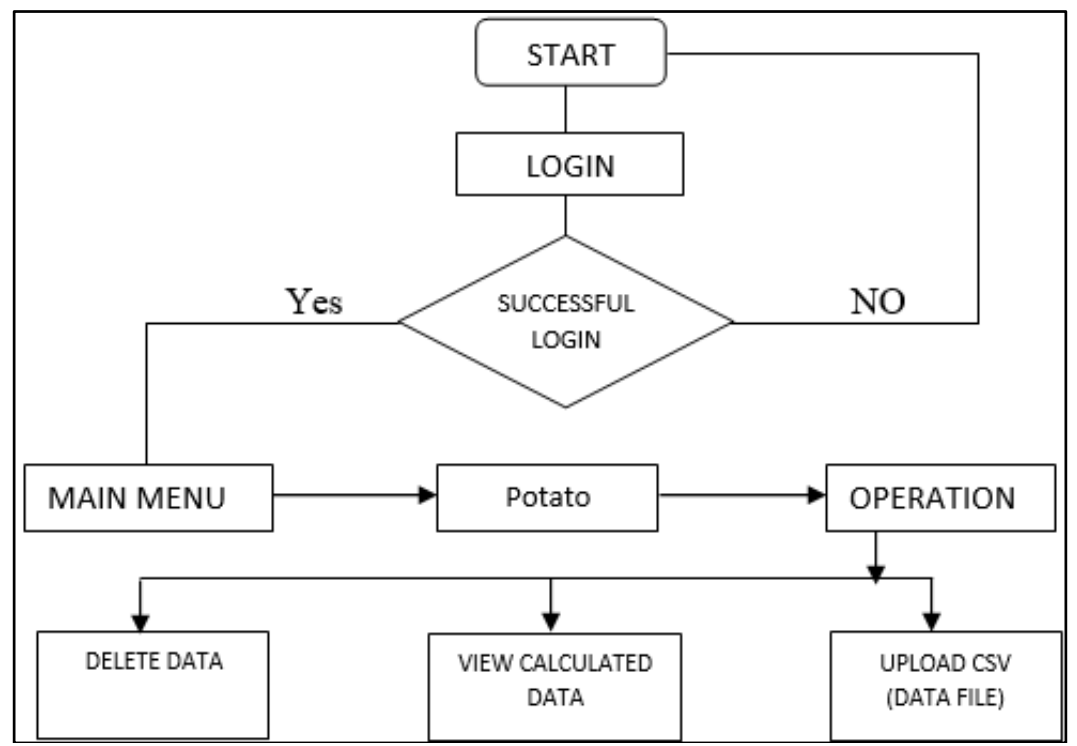

Fig 2: Frontend Flowchart of IFSS Model

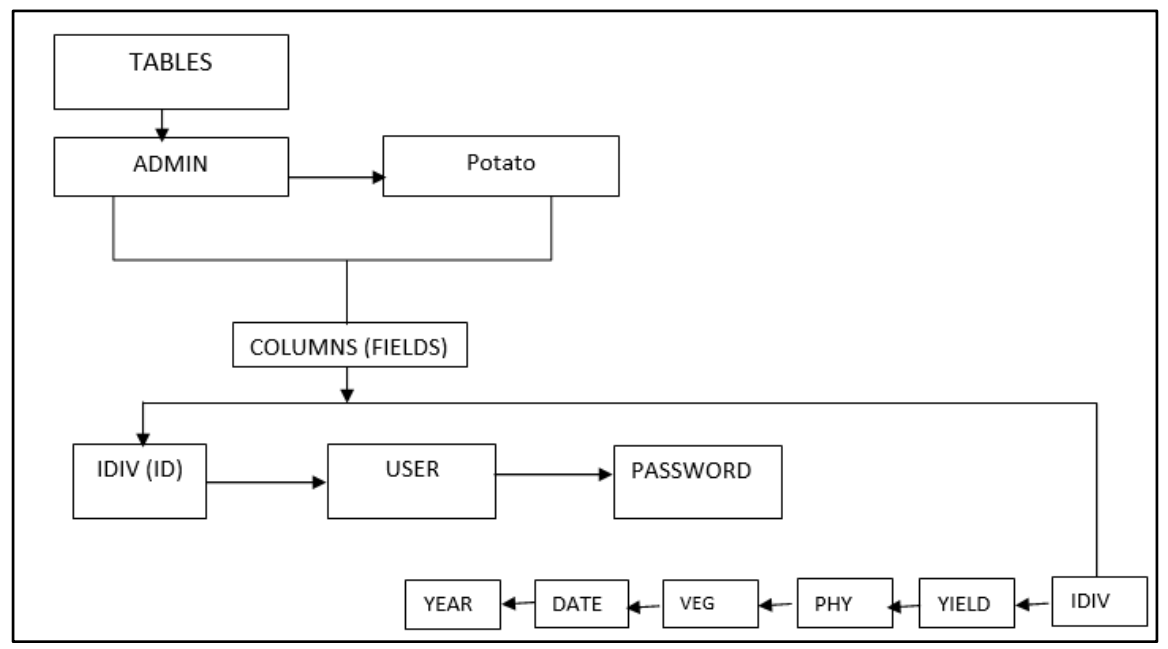

Fig 3: Database Structure Flowchart of Potato Model

\section{Software methodology of computational modeling}

The general methodology for computational modeling system is the design techniques are identification phase, conceptualization phase, formalization, system design \& development, testing/evaluation and prototype revision phase. Theoretical concepts and computational methods that describe, represent and simulate the functioning of real-world processes; computer simulations in agriculture system are becoming a 'third way' of performing research, expanding thus traditional experimental and theoretical approaches: simulation can be regarded as a numerical experiment, but it often requires advancements in theory simulations can provide information which is impossible or too expensive to measure, as well as insights which are not amenable or too complicated for analytical theory methods models are simplified abstractions of reality representing or describing its most important/driving elements and their interactions simulations can be regarded as model runs for certain initial conditions (real or designed) (K.S. Reddy 1992) ${ }^{[14]}$.

Traditional modelling placed emphasis on mathematical modeling with most models based on partial differential equations. As the vast majority of mathematical models are not solvable analytically, approximate methods and numerical methods are the alternative (Shaalan Khaled, 2004) ${ }^{[11]}$. Unless the solution behaves smoothly, it may be intractable even with approximate methods. In this case, the only feasible approach is numerical solution. However, even though we can in principle solve a complex system numerically; this does not mean it is trivial in practice. In fact, most research efforts in the last few decades have dedicated to finding the most efficient methods in solving complex systems (James Nolan et al. 2009) ${ }^{[9]}$. 
STEP-I: Open Chrome and type localhost on url. Then open software and select username and password. Administrator and user both can Login in this software.

STEP-II: Now, there will be open a panel where you see IFSSIMULATOR menus (MAIZE, MUSTARD, PIGEONPEA, POTATO, RICE, SUGARCANE, WHEAT, REGISTER USER

AND EXIT). Here, admin can choose or select any menu.

STEP-III: After selecting any menu browse and choose a file of selected menu and open

STEP-IV: Then, click on Upload File their will be open an alert box click ok

STEP-V: Now, admin select a year of which he want to see calculated data

STEP-VI : Now, Click on Get data button to fetch files and display files on down side

STEP-VII : Now, admin can choose a file and click on Get Calculated to see the data or can delete a file.

STEP-VIII : Back to menu and you can delete a file if want to delete the data of relevant menu.

STEP-IX: Admin can register a user after that user can upload the data and get calculate.
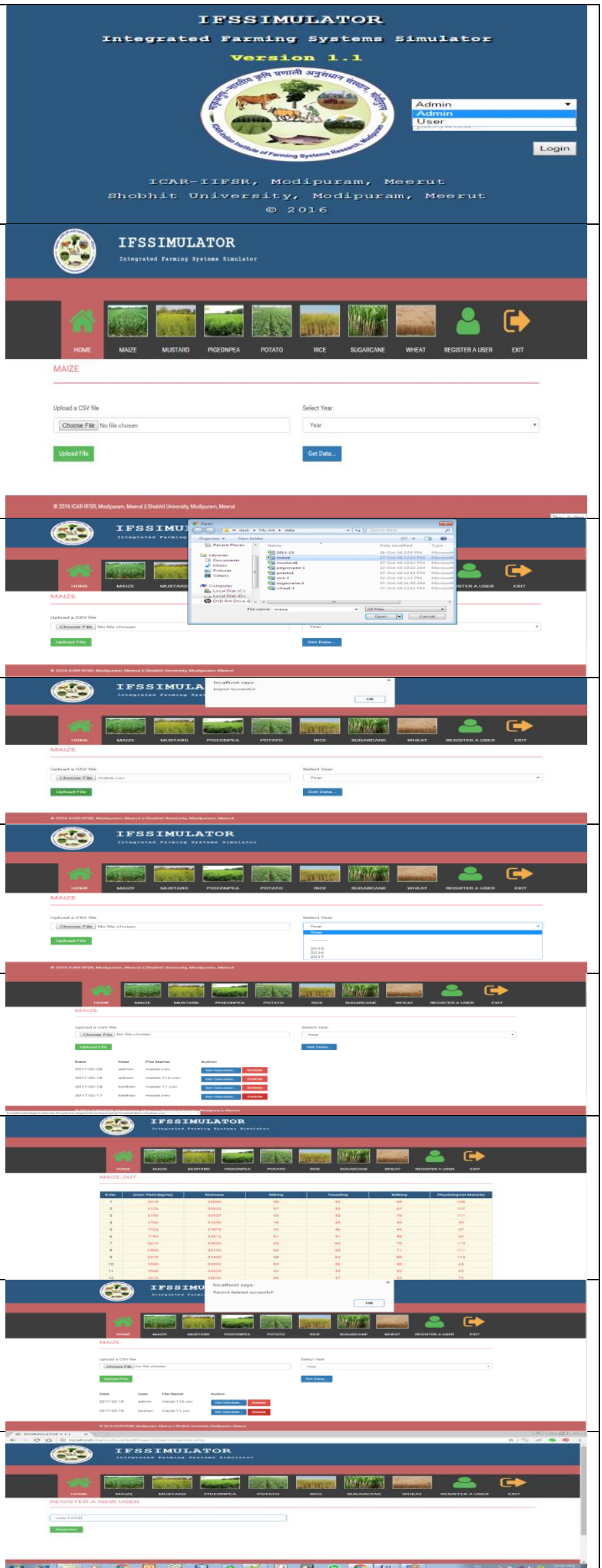

User can upload the data and get calculated the selected file data but can't delete the file. Only Admin can delete the file. In this user can calculated the own uploaded data only. But Admin can calculate and see the data uploaded by admin/a user.

\section{Results and Discussion}

Table 1 revealed that higher yield was obtained during 201314 as compared to $2014-15$ due to favorable climatic conditions in the year of study. The highest tuber yield (72961 $\mathrm{kg} / \mathrm{ha}$ ) was recorded in pond soil $\left(\mathrm{T}_{2}\right)$ in the Rabi 2013. The higher tuber yield of potato during 2013 \& 2014 was found in pond soil $\left(\mathrm{T}_{2}\right)$ followed by normal $\left(\mathrm{T}_{1}\right)$ and control $\left(\mathrm{T}_{3}\right)$. In 
general higher Tuber yield of potato was observed in Rabi2014 over the Rabi 2013 (S. Keller 2003) ${ }^{[10] .}$

The mean biomass $(\mathrm{kg} / \mathrm{ha})$ was recorded higher in treatment normal $\left(\mathrm{T}_{1}\right)$. The range of mean biomass of potato was $163793-165539 \mathrm{~kg} / \mathrm{ha}$. In the rabi2014, biomass was higher in comparison to rabi 2013. The trend of tuber yield was similar as in the trend of the biomass. Mean days to physiological maturity of the crops was recorded similar in normal $\left(\mathrm{T}_{1}\right)$ and pond soil $\left(\mathrm{T}_{2}\right)$ (133 days) followed by control $\left(\mathrm{T}_{3}\right)$ (127days). The trends of days to physiological maturity was pond soil $\left(\mathrm{T}_{2}\right)$ (130days) was highest followed by normal $\left(\mathrm{T}_{1}\right)$ and control $\left(\mathrm{T}_{3}\right)$ in 2013 and normal $\left(\mathrm{T}_{1}\right)$ (137days) was highest followed by pond soil $\left(\mathrm{T}_{2}\right)$ and control $\left(\mathrm{T}_{3}\right)$ in 2014 (Table 1) (Arnone, S. 1998) ${ }^{[1]}$.

Table 1: Tuber yield, biomass and physiological maturity of potato during rabi 2013-2014 and 2014-2015

\begin{tabular}{|c|c|c|c|c|c|c|c|c|c|}
\hline Treatments & \multicolumn{3}{|c|}{ Yield kg/ha. } & \multicolumn{3}{|c|}{ Biomass } & \multicolumn{3}{|c|}{ Physiological maturity } \\
\hline & 2013-2014 & 2014-2015 & Mean & 2013-2014 & 2014-2015 & Mean & 2013-2014 & 2014-2015 & Mean \\
\hline $\mathrm{T}_{1}$ & 71820 & 78242 & 75031 & 165650 & 165428 & 165539 & 129 & 137 & 133 \\
\hline $\mathrm{T}_{2}$ & 72961 & 78455 & 75708 & 166341 & 164721 & 165531 & 130 & 135 & 133 \\
\hline $\mathrm{T}_{3}$ & 70593 & 77090 & 73842 & 165076 & 162510 & 163793 & 124 & 130 & 127 \\
\hline
\end{tabular}

Table 2: Regression models for estimation of the tuber yield of potato

\begin{tabular}{|c|c|c|c|c|c|c|}
\hline \multicolumn{7}{|c|}{ Coefficientsa } \\
\hline Model & & Unstandardized Coefficients & Std. Error & Standardized CoefficientsBeta & $\mathbf{T}$ & Sig. \\
\hline \multirow{2}{*}{1} & (Constant) & 9637.756 & 14245.21 & & 0.677 & 0.508 \\
\hline & Physiological maturity & 498.727 & 108.85 & 0.753 & 4.582 & 0 \\
\hline
\end{tabular}

Out of 3 parameters related tuber yield of potato viz, biomass, and physiological maturity significantly contribute in the determination of tuber yield of potato, the coefficient of determination $\mathrm{R}^{2}=0.958$ is calculated following the stepwise regression analysis. The regression equation \{tuber yield $(\mathrm{kg} / \mathrm{ha})=9637.756+498.727 *$ (tuber maturity) $\}$ was fitted in the model for development of the software for decision support systems as a potato component/module (Table 2) (M. Coll, S et.al. .2000) ${ }^{[5]}$.

The results of crop yields and various yield attributing characters in terms of their respective actual values were compared with respectively those simulated by the model. The results are presented and discussed under titled paragraphs in pursuance of the objectives set forth for the study fig. $1 \mathrm{a} \& 1 \mathrm{~b}$ and Table $1 \& 2$.

\section{Equation}

Tuber Yield $(\mathrm{kg} / \mathrm{ha})=9637.756 *$ (tuber maturity $)+498.727$

In the Algorithm:

\$sql="select * from \$category where year='\$year"';

\$query=mysqli_query $(\$ c o n n, \$ s q l)$;

We use the query to fetch the data on the behalf of selecting category and year then the data will be fetched from the database according to the field which is used in the equation and the equation calculate the prediction for the yield.

And also display all the data of uploaded csv file through the while loop

while(\$row1=mysqli_fetch_array(\$query1))

$\{@$ \$sum+= \$row1['grain_yield'];

@ \$sum1+= \$row1['test_wt'];

@ \$sum2+= \$row1['panicle_initiation'];

@ \$sum3+= \$row1['flowering_day'];

@ \$sum4+= \$row1['milking_stage'];

@ \$sum5+= \$row1['dough_stage'];

@ \$sum6+= \$row1['tuber_maturity'];

\}echonumber_format $(\$$ sum $/ \$$ count, 2$)$;

echonumber_format $(\$ s u m 1 / \$$ count, 2$)$;

echonumber_format $(\$ s u m 2 / \$$ count, 2$)$;

echonumber_format $(\$ s u m 3 / \$$ count, 2$)$;

echonumber_format $(\$ s u m 4 / \$$ count, 2$)$;

echonumber_format(\$sum5/\$count,2);

echonumber_format (\$sum6/\$count,2);

in this algorithm we also used the number_format function which is used to print the values 0-infinite after decimal. echo $809.7+71.3 *(\$$ sum $1=\$$ data[test_weight $])+160 *$ $(\$$ sum $1=\$$ data[pi] $) \quad-100.3 * \quad(\$$ sum $1=\$$ data[flowering] $)-$ $21.5 *($ sum $1=\$$ data[milking $])+16 * \$$ sum $1=\$$ data $[$ dough $]+7.6$ $* \$$ sum $1=\$$ data[physiological $])$

\section{Compression of model for potato}

After examined the potato crop result presented in Table $1 \& 2$. It was evident from the table that during 2014-15 crop performed well as compared to 2013-14 irrespective of transplanting dates during experimentation. It might be due to better weather condition prevailed during crop season 201314 than the crop season 2014-15 i.e. sunshine hours, maximum temperature, rainfall intensity and equally distribution of rains during the entire crop season and relative humidity (Appendix-I). The daily sun shine hours were higher $(6.4 \mathrm{~h})$ during the year crop 2014-15 than the crop season 2013-14 (5.8 h), however, its obtained more yields of potato cultivars in the year 2014-15 than 2013-14. These results were found better for other statistically software analysis of potato crop. Therefore our present trial model was found much better result for other (excel) programme because accuracy of the existing model result was $\mathrm{R}^{2}=0.958$ than other model accuracy due to $\mathrm{R}^{2}=0.882$. The coefficient of determination was calculated under the following steps by regression analysis parameters viz, yield, biomass, and physiological maturity that affect the significant contribution in the determination of potato crop yield. Under the study area model used during experimentation was performed better accuracy as compared to other software. However, existing model is used more easy to predict the experimental finding elaborate or explained the crop performance.

Farmers were benefitted by the use of such model on their fields, use of models in farming was done to increase productivity and in turn livelihoods. Modeling technology like IFSS (Integrated Farming System Simulator ver.1.1) was developed for potato crop computational modeling for yield predictions in integrated farming system, which benefitted the entire farmer community in western Uttar Pradesh and also became popular in other regions of India.

\section{Conclusion}

Our results revealed that as an overall research challenge, the interoperability of data sources, modeling technology like IFSS (Integrated Farming System Simulator var.1.1), 
reference data sets for applications and specific user requirements analysis methodologies need to be addressed to allow agricultural modeling to enter in the big data era. This will enable much higher analytical capacities and the integrated use of new data sources. We believe that a the information in crop model and meteorological indicators to forecast crop yield Models community that follows these good practices and addresses the research agenda is likely to gain a substantial following and to spur increased collaboration within and between communities. We expect it to provide significantly enhanced tools to help deliver sustainable food production under both todays and tomorrow's changing climate conditions.

\section{Acknowledgement}

We are grateful to the authorities of the Indian Institute of Farming System Research, Modipuram Meerut, U.P. and Shobhit University Meerut, U.P. India for all support in execution of this experiment. We also acknowledge the technical support. Moreover, we would like to express our great respect for the editors and anonymous reviewers to improve the manuscript quality.

\section{References}

1. Arnone S, Musmeci L, Bacchetta N, Cordischi E, Pucci M, Cristofaro, et al. Research in Solanum spp. as sources of resistance to the potato tuber moth Phthorimaeaoperculella (Zeller). Potato Research. 1998; 41:39-49

2. Athanasiadis IN, Foster I, Jones JW, Antle JM. Towards a new generation of agricultural system models, data, and knowledge products: building an open web-based approach to agricultural data, system modeling and decision support. AgMIP<urltbd>, 2015.

3. Big Data: A New World of Opportunities, NESSI White Paper. Networked European Software and Services Initiative, NESS, 2012.

4. Carley KM. September, Validating Computational Models Department of Social and Decision Sciences, Carnegie Mellon University, 1996, 140.

5. Coll M, Gavish S, Dori I. Population biology of the potato tubermoth, Phthorimaeaopercuella (Lepidoptera: Gelechiidae) in two potato cropping systems in Israel. Bulletin of Entomological Research. 2000; 90:309-315.

6. Connell Mc, Douglas J, Dillon JL. Farm Management for ASIA: a system approach, FAO, Rome, 1997.

7. Gartner, Top 10 Technology Trends Signal the Digital Mesh. Gartner Inc, 2016.

8. Graft JE. The potato tubermoth. Tech. Bull. USDA. 1917; 427:58,

9. James Nelson. et al. An Overview of Computational Modeling in Agricultural. Resource Economics, 2009, 417-429.

10. Keller S, Kroschel J. Integrated pest management of the potato tuber moth in cropping systems of different agroecological zones. In Advances in Crop Research. 2003, 153.

11. Khaled S, El-Badry Mona, Rafea Ahmed. A multiagent approach for diagnostic expert systems via the internet; Expert Systems with Applications. 2004; 2:1-10.

12. Kumar S, Shamim M, Mamta, Gangwar B, Agarwal RP. Computational modeling and emerging trend in agriculture $2^{\text {nd }}$ International Conference on Computer for sustainable Global Development, Bharati Vidyapeeth's
Institute of computer and management (BVICAM), New Delhi (INDIA) $11^{\text {th }}-13^{\text {th }}, 2015$.

13. Miller JSE. Complex Adaptive Systems: An Introduction to Computational Models of Social Life. Princeton: Princeton University Press, 2007, 7.

14. Reddy KS, Reddy BB. Correlation coefficients for crop weather relationships in Potato. J Research, APAU. 1992; 20:85-87,

15. Singh M, Singh JP, Singh SP, Prasad K. Characterization and constraint analysis of farming system of Meerut district. Journal of Farming System Research and Development, 2005, 1-11.

16. Wallach D, Makowski D, Jones JW, Brun F. "Working with Dynamic Crop Models: Methods, Tools and Examples for Agriculture and Environment (Second Edition). Academic Press. Waltham, MA, 2014.

17. Wheeler $\mathrm{T}$, von Braun J. Climate Change Impacts on Global Food Security. Science. 2013; 341:508-513. 